\title{
Motivation to Learn, Quality of Life and Estimated Academic Achievement: Medical Students Studying in New Zealand
}

\author{
Marcus A. Henning ${ }^{1}$, Christian U. Krägeloh ${ }^{2}$, Susan J. Hawken ${ }^{1}$, \\ Iain Doherty ${ }^{1}$, Yipin Zhao ${ }^{1}$ \& Boaz Shulruf ${ }^{1}$ \\ ${ }^{1}$ University of Auckland, Auckland, New Zealand \\ ${ }^{2}$ AUT University, Auckland, New Zealand
}

\begin{abstract}
The quality of life of medical students and their motivation to learn are critical factors that have an impact on their ability to learn. The aim of this study was to investigate the associations between medical students' perceptions of their quality of life, motivation to learn, and estimated grade at the end of the academic year. Two hundred and seventy-four medical students at years four and five of medical school participated in the study. Students filled in a demographic survey form, and shortened versions of the World Health Organization Quality of Life Questionnaire and the Motivated Strategies for Learning Questionnaire. Significant correlations between quality of life and motivation to learn measures were obtained. Second, students who scored high on aspects of quality of life and motivation to learn also scored significantly higher on estimates of written grade. In conclusion, the results suggest that medical students' perceptions about quality of life and motivation to learn are linked to estimation of academic achievement. The findings of this study further resonate with a key conceptual model in the motivation literature, which promotes the importance of creating opportunities for mastery learning, engaging task value, producing optimal learning contexts, and creating mechanisms for coping with and managing the inevitable anxiety-provoking learning experiences that medical students face.
\end{abstract}

\section{Introduction}

The quality of life (QoL) of medical students and their motivation to learn (MtL) are critical factors that have an impact on their ability to learn. ${ }^{1}$ There is considerable interest in medical students and the driving forces that underpin their learning process. ${ }^{2}$ The well-being of medical students is well researched, and some links have been made between students' quality of life and their motivation to learn, and scholastic achievement. , 3-11 $^{1-1}$ Nevertheless, research in this area is often ad hoc and more research is required to determine the relationships between QoL and MtL using theoretical paradigms and established robust research tools such as those developed by the World Health Organization and prominent motivational theorists. ${ }^{12-16}$

Corresponding author: Marcus A. Henning, PhD, Senior Lecturer, Centre for Medical and Health Sciences Education, Private Bag 92019, University of Auckland, Auckland 1142, New Zealand. Tel: +64-9-3737599 ext 87392, Fax: +64-9-3737204, Email: m.henning@auckland.ac.nz
Numerous studies have documented QoL issues amongst the medical student population. ${ }^{1,}{ }^{3-6}$ For example, research has indicated the adverse impact of medical education on student well-being, and these issues have been linked to the intense nature of the academic, clinical, and professional demands made during training and problems related to finance and expectations from staff and parents.4,5,17-19 The notion of QoL has been defined by the World Health Organization (WHO) as "individuals' perceptions of their position in life in the context of the culture and value systems in which they live and in relation to their goals, expectations, standards and concerns". ${ }^{20}$ From this conceptual definition, the WHO produced several instruments that provide subjective, cross-culturally applicable, psychometrically sound, and multidimensional measures of QoL. ${ }^{21}$ The abbreviated version of the WHO quality of life questionnaire series (the WHOQOL-BREF) was used in the present investigation to measure QoL. 
MtL as an academic concept, in reference to student learning, has been explained in terms of the expectancy-value theory that encompasses aspects of self-efficacy, intrinsic value, test anxiety, effort regulation, and the use of cognitive and metacognitive strategies. ${ }^{14}$ Expectancy value theory clearly indicates that how students perceive themselves (i.e., self-esteem) or their emotional reactions to situations or environments are integrally related to the motivational process. ${ }^{16}$ In a detailed paper, MtL was framed in terms of several components that begin with the personal characteristics of the student (age, gender, ethnicity) and the classroom context (the content of the academic material and the process by which this is taught). ${ }^{16}$ These components act upon the motivational and self-regulatory aspects of the learning process and are likely moderated by quality of life issues. The final component relates to outcomes (academic grades and sense of achievement in terms of applied effort). In line with this theory, it has been suggested that medical students tend to be intrinsically motivated and this enhances their ability to persevere in their studies and thus academically achieve. ${ }^{22-24}$

Tanaka and others established a link between intrinsic motivation and the need for students to have a balanced lifestyle with higher levels of intrinsic motivation leading to higher levels of selfdirection, co-operation and engagement in selfdiscovery. 9 Lonka and others constructed a questionnaire with domains associated with $\mathrm{MtL}$ and QoL.7 However, this study did not address key areas such as self-efficacy and levels of engagement; nor did it consider aspects of academic achievement. In addition, the validity data for the questionnaire was not convincing for factors such as social orientation and individual abilities orientation. These research outcomes suggest that there is much more work to be done in terms of investigating the areas of QoL and MtL, particularly in relation to the medical learning environment.

The purpose of the present study is to consider the impact of QoL and MtL on academic performance. The research question for the study was, "Do medical students who estimate high levels of academic attainment have higher levels of QoL and MtL than students with lower expectations?" It was expected that students with high academic expectations would generate higher ratings in comparison with students with lower expectations. ${ }^{22-24}$

\section{Methods \\ Participants}

Two hundred and seventy four medical students (response rate of $80 \%$ out of a total of 343 students enrolled in fourth and fifth year at medical school) participated in the present study; this exceeds the accepted response rate of $60 \% .25$ The average age of the sample was 22.74 years $(\mathrm{SD}=2.75)$. The sample comprised of self-selected volunteers (150 female, 122 male, 2 missing data) chosen from two clinical years $\left(165\right.$ from $4^{\text {th }}$ year from a total of 183,108 from $5^{\text {th }}$ year from a total of 160,1 missing datum). Various ethnic groups were self-identified (97 Asian, 99 European, 14 Maori, 14 Pacific island, 47 Other, 3 missing data).

\section{Procedure}

The University of Auckland has a six year undergraduate medical course, consisting of three years of predominantly basic science followed by three years focussed on clinical teaching. The students surveyed in this study were in their first two clinical years (fourth and fifth years of the medical course). The final year of the course is a pre-intern year where students are supervised and work as a first year intern. ${ }^{26}$ This study was conducted between March and June in 2009. The students were asked to fill in the anonymous questionnaires in a lecture theatre at the end of formal class time and the questionnaires were collected by three research personnel. It was decided that utilizing anonymous questionnaires would likely yield more honest answers to sensitive questions related to quality of life issues in contrast to confidential questionnaires, hence eliminating the problem of social desirability. ${ }^{27}$ However, it is acknowledged that there is an interesting debate in the literature concerning the use of anonymous versus confidential surveys. ${ }^{28}$ In addition, incorporating the anonymous questionnaires format removed the possibility of obtaining actual performance data. The questionnaires consisted of a demographic survey, the Australian version of the World Health Organization questionnaire (WHOQOL-BREF) and a shortened version of the Motivated Strategies for Learning Questionnaire (MSLQ). ${ }^{14,29}$ During the time that the present study was conducted, a New Zealand version of the instrument was still in development and, thus, the Australian version was chosen, as it was deemed the most culturally relevant version to New Zealand. ${ }^{29}$ 


\section{Measures}

Three main measures were incorporated into the study design. These were: background details; the WHOQOL-BREF; and MSLQ data.

The background details, relevant to the present study, included year of study, age, gender, and students' estimated clinical attachment grade and their estimated end of year grade for written examinations. The estimated grade options were distinction, clear pass, pass, or fail. The official clinical grading system used in this New Zealand medical school (for both years 4 and 5) centre around: (1) Distinction - Student is performing at a high standard. Student has very good underpinning knowledge, excellent clinical skills and contributes to the group/team. Approach to patient management shows evidence of sound clinical judgment and balanced, prioritized planning; (2) Pass - Student is performing at an expected standard. Underpinning knowledge and clinical skills are satisfactory with some contribution to the group/team. Has adequate problem orientation and management planning which would ensure good patient care and safety. No inappropriate management, and (3) Fail - Student is performing at an unacceptable standard. Student has poor underpinning knowledge, significant gaps in clinical skills, and does not contribute to group/team. Irrational or poor judgment which may threaten patient care or safety. Written examinations are evaluated in terms of $\mathrm{A}+, \mathrm{A}, \mathrm{B}+, \mathrm{B}, \mathrm{C}+, \mathrm{C}$, and $\mathrm{D}$. The estimated grading criteria used in the study were developed by a faculty staff member who had worked with this student cohort to create more variance for the clinical grades and consistency across clinical and written grading systems. The 26item WHOQOL-BREF Australian version used in this study includes two general items (1 and 2) and 24 items that encompass four domains (namely, physical health, psychological health, social relationships, and environmental conditions).29 All items are presented on a 5-point Likert scale, with three reversed items (3, 4, and 26). High scores for each domain represent higher levels of QoL and lower scores the converse.

An abbreviated version of the MSLQ was used for this study. ${ }^{14}$ This version has 44 items and two scales, specifically motivational beliefs and selfregulated learning strategies. The motivational beliefs scale includes the subscales self-efficacy, intrinsic value, and test anxiety. The self-regulated learning strategies scale consists of the subscales cognitive strategy use (i.e., rehearsal, elaboration and organizational strategies) and self-regulation (i.e., meta-cognition and effort regulation). As with the QoL measures, each item requires a 5-point Likert response. In addition, high scores for each subscale represent higher levels of motivation or self-regulation with the exception of test anxiety, where high scores indicate increased anxiety.

\section{Data Analysis}

The statistical software PASW version 18 (formerly SPSS) was used to compute the following statistics.30

Preliminary analyses. First, to check the reliability of the instruments, Cronbach's alpha scores were generated for each domain and subscale. Second, levels of association between the WHOQOL-BREF domains and the MSLQ subscales were evaluated using Pearson correlations.

Main analyses. A multivariate analysis of covariance MANCOVA was initially instigated to assess the impact of potential confounding variables such as age, gender, and year of study. To assess the within-group variances of the medical students' cohort a multivariate analysis of variance (MANOVA) approach was then employed. Estimated academic attainment (written), year of study and gender were considered as independent variables, and the WHOQOL-BREF and MSLQ measures were dependent variables.

\section{Ethics}

Ethics approval for the collection and use of data was obtained from the University of Auckland Human Participants Ethics Committee on April 15, 2009.

\section{Results}

\section{Preliminary analyses}

Reliability coefficients.

The Cronbach alpha scores for each of the WHOQOL domains and MSLQ sub-scales were within acceptable limits. ${ }^{30}$

1. WHOQOL-BREF: Physical health (.76), psychological health (.77), social relationships (.74), and environment (.76).

2. MSLQ: Self-efficacy (.90), intrinsic value (.81), test anxiety (.84), cognitive strategy use (.70), and self-regulation (.60).

Correlation analyses between QoL and MtL indicators.

Table 1 below presents Pearson correlations for the WHOQOL-BREF domain scores against the MSLQ subscale scores. Significant correlations $(\mathrm{p}<.05)$ 
were noted for intrinsic value, self efficacy, and selfregulation on all QoL domains. Test anxiety was negatively correlated with three of the QoL domains (physical health, psychological health and environment), and cognitive strategy use with one QoL domain (social relationships). These results, thus, indicate significant inter-correlation between the concepts of QoL and MtL, but the low magnitudes of the correlations suggest a large amount of unexplained variance.

\begin{tabular}{|l|l|l|l|l|l|}
\hline \multicolumn{2}{|l|}{ MSLQ subscales } \\
\hline $\begin{array}{l}\text { WHOQOL } \\
\text { Domains }\end{array}$ & $\begin{array}{l}\text { Intrinsic } \\
\text { value }\end{array}$ & $\begin{array}{l}\text { Self- } \\
\text { efficacy }\end{array}$ & $\begin{array}{l}\text { Test } \\
\text { anxiety }\end{array}$ & $\begin{array}{l}\text { Cognitive } \\
\text { strategy } \\
\text { use }\end{array}$ & $\begin{array}{l}\text { Self- } \\
\text { regulation }\end{array}$ \\
\hline Physical health & $.23^{*}$ & $.31^{*}$ & $-.24^{*}$ & .03 & $.18^{*}$ \\
\hline $\begin{array}{l}\text { Psychological } \\
\text { health }\end{array}$ & $.26^{*}$ & $.27^{*}$ & $-.33^{*}$ & .11 & $.23^{*}$ \\
\hline $\begin{array}{l}\text { Social } \\
\text { relationships }\end{array}$ & $.15^{*}$ & $.15^{*}$ & -.11 & $.15^{*}$ & $.14^{*}$ \\
\hline Environmental & $.24^{*}$ & $.23^{*}$ & $-.33^{*}$ & .04 & $.17^{*}$ \\
\hline
\end{tabular}

Table 1. Pearson correlations for the $W H O Q O L-B R E F$ domains and the MSLQ subscales. ${ }^{*} p<.05$.

\section{Main analyses: Student estimates of grade}

A MANCOVA (Table 2) was instigated to evaluate possible differences between students with high academic expectations versus those with lower expectations. This was conducted to address the overriding research question, namely what are the associations between medical students who estimate high levels academic attainment compared to those with lower expectations in relation to QoL and MtL perceptions.

The MANCOVA incorporated end-of-year estimates (distinction; clear pass; pass) of clinical and written grades in terms of the dependent variables the WHOQOL-BREF and MSLQ measures. No students checked the 'fail' option. Potential confounding variables - age, gender and year of study (year 4; year 5) - were included in this analysis.

A significant multivariate result, using Wilks' Lambda, was found for written grade $\mathrm{F}(18,444)=$ $1.93, \mathrm{p}=.01$ and gender $\mathrm{F}(9,222)=2.32, \mathrm{p}=.02$. One interaction effect was noted between year of study and gender $\mathrm{F}(9,222)=3.28, \mathrm{p}=.00$ No other significant differences were noted.

\begin{tabular}{|l|c|c|c|c|c|}
\hline Effect & Value & $F$ & $\begin{array}{c}\text { Hypothesis } \\
\text { df }\end{array}$ & $\begin{array}{c}\text { Error } \\
\text { df }\end{array}$ & $p$ \\
\hline Age & .94 & 1.50 & 9 & 222 & .15 \\
\hline Year (Y) & .952 & 1.24 & 9 & 222 & .27 \\
\hline Gender (G) & .91 & 2.32 & 9 & 222 & $.02^{*}$ \\
\hline $\begin{array}{l}\text { Clinical } \\
\text { grade (CG) }\end{array}$ & .94 & .85 & 18 & 444 & .64 \\
\hline $\begin{array}{l}\text { Written } \\
\text { grade (WG) }\end{array}$ & .86 & 1.93 & 18 & 444 & $.01^{*}$ \\
\hline $\mathrm{Y}^{*} \mathrm{G}$ & .88 & 3.28 & 9 & 222 & $.00^{*}$ \\
\hline $\mathrm{Y}^{*} \mathrm{CG}$ & .91 & 1.25 & 18 & 444 & .22 \\
\hline $\mathrm{Y}^{*} \mathrm{WG}$ & .92 & 1.02 & 18 & 444 & .43 \\
\hline $\mathrm{CG}{ }^{*} \mathrm{G}$ & .95 & .70 & 18 & 444 & .81 \\
\hline $\mathrm{WG}{ }^{*} \mathrm{G}$ & .94 & .79 & 18 & 444 & .71 \\
\hline $\mathrm{CG}{ }^{*} \mathrm{WG}$ & .92 & 1.04 & 18 & 444 & .41 \\
\hline $\mathrm{Y}^{*} \mathrm{G}^{*} \mathrm{CG}$ & .95 & 1.44 & 9 & 222 & .17 \\
\hline $\mathrm{Y}^{*} \mathrm{G}^{*} \mathrm{WG}$ & .94 & .74 & 18 & 444 & .77 \\
\hline $\mathrm{Y}^{*} \mathrm{CG}{ }^{*} \mathrm{WG}$ & .92 & 1.09 & 18 & 444 & .36 \\
\hline $\mathrm{G}^{*} \mathrm{CG}{ }^{*} \mathrm{WG}$ & .95 & .63 & 18 & 4444 & .88 \\
\hline
\end{tabular}

Table 2. Multivariate results (Wilks' Lambda) for the MANCOVA for estimated clinical and written grades in terms of the four WHOQOL and five MSLQ measures

A MANOVA analysis was then conducted by removing age from the statistical procedure as a confounder but retaining year of study and gender as independent variables. The tests of betweensubject effects for written grade (Table 3 ) showed significant effects for the WHOQOL-BREF domains of physical health $(\mathrm{F}(2)=3.68, \mathrm{p}=.03)$, psychological health $(\mathrm{F}(2)=7.08, \mathrm{p}=.00)$, and social relationships $(\mathrm{F}(2)=4.60, \mathrm{p}=.01)$. Further significant effects were noted for the MSLQ subscales of self-efficacy $(\mathrm{F}(2)=26.70, \mathrm{p}=.00)$, intrinsic value $(\mathrm{F}(2)=5.86, \mathrm{p}=.00)$, test anxiety $(\mathrm{F}(2)=10.95, \mathrm{p}=.00)$, and self-regulation $(\mathrm{F}(1)=$ $5.86, \mathrm{p}=.00)$. Close to significant differences $(\mathrm{p}<.05)$ were noted for environment $(\mathrm{F}(2)=2.95$, $\mathrm{p}=.05)$ and cognitive strategy use $(\mathrm{F}(2)=2.98$, $\mathrm{p}=.05)$.

The mean values and standard deviations (Table 4) are shown for each of the WHOQOL-BREF domains and MSLQ subscales for the estimated written grade options of distinction, clear pass and pass. 


\begin{tabular}{|l|c|c|c|c|}
\hline Effect & df & $\begin{array}{c}\text { Mean } \\
\text { Square }\end{array}$ & $F$ & $p$ \\
\hline Physical health & 2 & .69 & 3.68 & .03 \\
\hline Psychological health & 2 & 1.44 & 7.08 & .00 \\
\hline Social relationships & 2 & 2.87 & 4.60 & .01 \\
\hline Environment & 2 & .97 & 2.95 & .05 \\
\hline Self-efficacy & 2 & 7.56 & 26.70 & .00 \\
\hline Intrinsic value & 2 & 1.30 & 5.86 & .00 \\
\hline Test anxiety & 2 & 7.53 & 10.95 & .00 \\
\hline Cognitive strategy Use & 2 & .61 & 2.98 & .05 \\
\hline Self-regulation & 2 & 2.27 & 11.21 & .00 \\
\hline
\end{tabular}

Bonferroni post-hoc tests revealed that measures of those students expecting 'distinction' grades were significantly higher $(\mathrm{p}<.05)$ than those expecting 'pass' grades on all WHOQOL domains and MSLQ sub-scales, except for test anxiety, where 'distinction' grade students had significantly lower scores. Secondly, students expecting a 'clear pass' scored significantly higher than those students identifying as 'pass' students (Bonferroni tests, p < .05) on all measures except social relationships, environment and self-regulation, and significantly lower on text anxiety. Lastly, 'distinction' students had significantly higher scores than 'clear pass' students on the measures self-efficacy and selfregulation (Bonferroni tests, $\mathrm{p}<.05$ ).

Table 3. Tests of between-subject effects showing the estimated written grade results over the four WHOQOL and five MSLQ measures

\begin{tabular}{|l|c|c|c|}
\hline & \multicolumn{3}{|c|}{ End of year written assessment grades } \\
\hline & $\begin{array}{c}\text { Distinction } \\
(n=36)\end{array}$ & $\begin{array}{c}\text { Clear Pass } \\
(n=201)\end{array}$ & $\begin{array}{c}\text { Pass } \\
(n=26)\end{array}$ \\
\hline $\begin{array}{l}\text { WHOQOL- } \\
\text { domains }\end{array}$ & $M(S D)$ & $M(S D)$ & $M(S D)$ \\
\hline Physical health & $3.19(.49)^{\dagger}$ & $3.12(.42)^{\ddagger}$ & $2.93(.50)$ \\
\hline $\begin{array}{l}\text { Psychological } \\
\text { health }\end{array}$ & $3.63(.46)^{\dagger}$ & $3.50(.44)^{\ddagger}$ & $3.17(.55)$ \\
\hline $\begin{array}{l}\text { Social } \\
\text { relationships }\end{array}$ & $4.05(.77)^{\dagger}$ & $3.75(.76)$ & $3.35(1.10)$ \\
\hline Environment & $3.81(.61)^{\dagger}$ & $3.78(.54)$ & $3.43(.75)$ \\
\hline MSLQ - subscales & $3.93(.50)^{* \dagger}$ & $3.43(.55)^{\ddagger}$ & $2.82(.52)$ \\
\hline Self-efficacy & $4.14(.49)^{\dagger}$ & $3.94(.46)^{\ddagger}$ & $3.65(.52)$ \\
\hline Intrinsic value & $2.47(.97)^{\dagger}$ & $2.81(.83)^{\ddagger}$ & $3.44(.86)$ \\
\hline Test anxiety & $3.78(.70)^{\dagger}$ & $3.57(.46)$ & $3.35(.38)$ \\
\hline $\begin{array}{l}\text { Cognitive Strategy } \\
\text { Use }\end{array}$ & $3.83(.34)^{* \dagger}$ & $3.48(.48)$ & $3.25(.31)$ \\
\hline Self-regulation & & & \\
\hline
\end{tabular}

${ }^{*} p<.05$ for Distinction versus Clear Pass

$\dagger p<.05$ for Distinction versus Pass

$\neq p<.05$ for Clear Pass versus Pass

Table 4. Means and standard deviations of the WHOQOLBREF domains and MSLQ subscales by estimated end of year written assessment grades

In summary, Table 1 presents evidence of significant correlations between QoL and MtL measures. Table 2 confirms that estimation of written grade is linked to areas of MtL and QoL, and that year of study and gender may influence this association. However, clinical grade estimation is not linked to areas of QoL and MtL. Table 3 clearly shows that estimated written grade is related to nearly all of the subdomains of QoL and MtL measured in this study. Finally, Table 4 presents compelling trends for all sub-domains QoL and MtL in reference to estimated written grade, and that in all cases there are convincing trends to suggest that wellness is related to achievement. It is important to note, that test anxiety is negatively correlated with wellness.

\section{Discussion}

The focus of this research was to consider students' estimated grade average for written and clinical examinations and associations with QoL and MtL.

\section{Preliminary analyses}

First, the measures used in this study were found to be reliable and thus suitable for this area of study. Second, the findings in the present study revealed that all the QoL indicators were uniformly correlated with self-efficacy, intrinsic value, and self-regulation, and that test anxiety was negatively correlated with the physical health, psychological health and environmental QoL domains. This is a similar result to other studies indicating comparable links between QoL and MtL.7, 9, 31 Tanaka and others investigated the correlations between motivation, temperament, and character development; the findings of their study indicated significant positive correlations between intrinsic motivation and persistence, self-directedness and cooperativeness. ${ }^{9}$ 
In a further study, Lonka and others investigated the area of QoL and motivation.7 They found significant correlations between social orientation, collaborative knowledge building, reflective learning and valuing meta-cognition. These results are consistent with the significant correlations found, in this study, between social relationships and intrinsic value and self-regulation. Furthermore, these researchers found strong correlations between dysfunctional orientations and stress, lack of regulation, anxiety and exhaustion, which are similar to the findings in the present study that revealed significant correlations between psychological well-being, self-regulation and test anxiety.7 However, the present study extends the research of Lonka and others in several ways.7 First, the correlations are significant across the board (except for cognitive strategy use), although there was a large amount of unexplained variance. This pattern of significant correlations suggests that the QoL indicators and MtL factors could be measuring comparable entities, such as psychological wellbeing. Second, the present study has used two wellestablished instruments that demonstrate psychometric validation. ${ }^{14,}{ }^{2}$

A reasonable assertion at this point, and one that is consistent with the nature of medical education, is that well-being and the experience of study are two interacting themes reinforcing a holistic model of education that considers the whole student in terms of body, affect, cognition, and behavior. ${ }^{1,3} 33$ It is also likely that MtL and QoL are integrated aspects of learning, whereby each aspect influences the other in a symbiotic manner and that this moderating process likely impacts academic achievement. ${ }^{16,}, 34$

Investigations in this area will likely provide fruitful insight into how QoL and MtL interact and further inform areas such as selection of medical students, utilization of teaching methods, modeling of self care, promoting resilience, facilitating the use of good study habits and considering strategies for coping with examination stress. 35 Consequently, the medical students' learning environment likely affects their QoL and vice versa, and this interaction will likely continue into their professional lives as doctors and probably has implications for continuing medical education.

\section{Main analyses: Student estimates of grade}

It has been shown that student estimations of academic achievement are related to their academic self-concept or their perceptions and beliefs with respect to their academic abilities..$^{6}$ Furthermore, there is considerable evidence to suggest that academic self-concept is linked with actual academic performance, and that the link may be mediated by the use of learning strategies. ${ }^{10}, 37,38$ The findings in the present study suggest that students' perceptions about doing well in relation to their written examinations (i.e., achieve a distinction grade versus attaining a pass grade) are significantly able to discern students' perceptions about QoL and MtL. This finding was consistent across all QoL and MtL indicators. Similar differences were noted between 'clear pass' students and 'pass' students (except for self-regulation). Differences were noted only for self-regulation and self-efficacy when 'distinction' students were compared with 'clear pass' students.

It was interesting that the estimated written examination grades were in significant alignment with QoL and MtL issues, while clinical grade estimation showed no linkage. This result may indicate that this medical student group are less able to gauge their clinical competency (as compared with written proficiency) given that this is a new aspect of their learning, while they have already had three to four years - if not more - of written examinations at the university level. Consequently, they are likely to feel unclear and less confident about clinical grade (in comparison to written) given the greater variability in clinical assessments and that they are clearly clinical novices (even early in year five). 39 The interesting interaction found in this study between year of study and gender may be an area for further investigation. This finding indicates that changes over time influence male and females students differently.

In terms of QoL, there is evidence in the literature to indicate that scholastic achievement is correlated with QoL indicators. ${ }^{10}$, 11 For example, Chow found that scholastic achievement was moderated by quality of work-life balance, physical health, psychological well-being, development of social networks, family connections, and parents' level of education and socio-economic status. ${ }^{11}$ In addition, Ruthig and others found that higher levels of reported depression predicted lower levels of degree commitment and poorer cumulative grade point average. ${ }^{10}$ These findings are consistent with those of the present study and indicate the importance of cultivating positive intrapersonal and interpersonal development and well-being in enabling students to achieve their academic goals. 
The findings of this study also show that MtL and estimated written academic achievement are linked. Pintrich and Zusho have detailed a conceptual model based on social cognition theory. ${ }^{16}$ The model clearly shows that MtL has an impact on outcomes in terms of academic achievement. According to this model students' motivation to learn relates to the way they make choices in their learning environment, and this choice process is moderated by aspects of self-belief (self-efficacy), levels of interest (intrinsic value), and emotional well-being (task anxiety). Furthermore, the way in which students implement self-regulatory strategies also impacts on grade outcome such as how they plan and approach their academic goals. The present findings clearly show that motivational beliefs (selfefficacy, intrinsic value, and test anxiety) are related to perceptions about grade achievement in written tasks. These findings augment a convincing argument to suggest that students who believe they will do well are more likely to do well in terms of academic achievement and academic competence.4044 This result is an important finding for students, as educationalists need to inculcate innovative teaching practices to allow students to shift in terms of their academic self-concept and self-motivation to allow for change as required. It is further important to consider within group differences such as gender and year of study. And this is particularly pertinent for medical students who are under constant pressure to adapt to diverse educational and work environs.

Furthermore, the findings of this study support the key implications of Pintrich and Zusho's conceptual model. ${ }^{16}$ More specifically, the model provides clear clues as to how to improve the well-being and academic competencies of students through: understanding the complex and interrelated system of how QoL affects MtL and vice versa, creating opportunities for mastery learning, engaging task value, optimizing learning contexts, and creating mechanisms for coping with and managing the inevitable anxiety related scenarios. Moreover, the present findings extend the Pintrich and Zusho's model by embracing a wider set of factors that include physical and environmental quality of life factors that are integral to the process of learning, and thus, the clues above need to include feasible strategies that consider these aspects of wellness. ${ }^{16}$

There are a number of limitations with this study. First the study focuses on self-report data gathered from medical students embarking on their clinical training (years four and five) and, therefore, these findings may not be generalized to other students at different stages of their training. Furthermore, the definitions of the grading criteria used in this study would need to be more clearly defined in future research and this investigation would have been strengthened had we obtained actual grade achievements. However, this may have created difficulties as the anonymous nature of the study would have changed to a confidential one thus possibly influencing the responses given. Secondly the study has involved only one of the two major medical training universities in New Zealand. Third, the assumption of independent random sampling was not adhered to as participation was voluntary, although the high response rate increases the likelihood of representativeness. In addition, a major strength of the study is that it has incorporated two robust and reputable self-report mechanisms, namely WHOQOL-BREF and MSLQ.

\section{Conclusion}

The present study was conducted to investigate the associations between medical students who estimate high levels academic attainment compared to those with lower expectations in relation to QoL and MtL perceptions. From a review of the literature, the authors expected that students with high academic expectations would generate higher QoL and MtL ratings in comparison with students with lower expectations. ${ }^{22-24}$ However, the extent and magnitude of these connections were unclear.

The findings of the present study clearly show the connection between perceptions of academic outcome and perceptions about QoL and MtL. This connection was established with respect to written examinations, such that students who feel they will do well appear to have higher perceptions with regards their QoL and MtL, and students who feel that they will do less well are likely to be experiencing relatively more problems associated with QoL and MtL. It is proposed that open discussion and strategic interventions be interweaved in the curriculum about QoL and MtL to ensure greater levels of wellness thus optimizing learning capacity. It is further suggested that Pintrich and Zusho's conceptual model be used as a foundation framework to consider educational implications with respect to these findings. ${ }^{16}$ In addition, interventions of this nature need to be rigorously researched before formal implementation. 


\section{Notes on Contributors}

MARCUS A. HENNING, PhD, Senior Lecturer, Centre for Medical and Health Sciences Education, University of Auckland, Auckland, New Zealand.

CHRISTIAN U. KRÄGELOH, PhD, Senior Lecturer, Department of Psychology, AUT University, Auckland, New Zealand.

SUSAN J. HAWKEN, MBChB Dip Obs FRNZCGP MHSc (Hons), Senior Lecturer, Department of Psychological Medicine, Faculty of Medical and Health Sciences, University of Auckland, University of Auckland, Auckland, New Zealand.

IAIN DOHERTY, PhD, Senior Lecturer, Learning Technology Unit, University of Auckland, Auckland, New Zealand.

YIPIN ZHAO, BA Hons, Research Assistant, Centre for Medical and Health Sciences Education, University of Auckland, Auckland, New Zealand.

BOAZ SHULRUF, PhD, Senior Lecturer, Centre for Medical and Health Sciences Education, University of Auckland, Auckland, New Zealand.

\section{Keywords}

Medical students, motivation to learn, quality of life, New Zealand

\section{References}

1. Bramness JG, Fixdal TC, Vaglum P. Effect of medical school stress on the mental health of medical students in early and late clinical curriculum. Acta Psychiatrica Scandinavica. 2007; 84 (4):340-5.

2. Misch D. Andragogy and medical education: are medical students internally motivated to learn? Adv. Health Sci. Educ. 2002; 7 (2):153-60.

3. Hassed C, Lisle Sd, Sullivan G, Pier C. Enhancing the health of medical students: Outcomes of an integrated mindfulness and lifestyle program. Adv. Health Sci. Educ. 2009; 14 (3):387-98.

4. Radcliffe C, Lester H. Perceived stress during undergraduate medical training: A qualitative study. Med. Educ. $2003 ; 37$ (1):32-8.

5. Ross S, Cleland J, Macleod MJ. Stress, debt and undergraduate medical student performance. Med. Educ. 2006; 40 (6):584 - 9.

6. Srivastava K, Raju M, Saldanha D, Chaudhury S, Basannar D, Pawar A, et al. Psychological well-being of medical students. Med. J. Armed Forces India. 2007; 63 (2):137-40. Retrieved from http://medind.nic.in/maa/to7/i2/maat o7i2p.pdf.
7. Lonka K, Sharafi P, Karlgren K, Masiello I, Nieminen J, Birgegård G, et al. MED NORD-A tool for measuring medical students' well-being and study orientations. Med. Teach. 2008; 30 (1):72-9.

8. Owens J. Sleep loss and fatigue in medical training. Curr. Opin. Pulm. Med. 2001; 7 (6):411.

9. Tanaka M, Mizuno K, Fukuda S, Tajima S, Watanabe Y. Personality traits associated with intrinsic academic motivation in medical students. Med. Educ.. 2009; 43 (4):384-7.

10. Ruthig JC, Haynes TL, Stupnisky RH, Perry RP. Perceived Academic Control: mediating the effects of optimism and social support on college students' psychological health. Soc. Psychol. Educ. 2009; 12 :233-49.

11. Chow HPH. Psychological well-being and scholastic achievement among university students in a Canadian Prairie City. J. Soc. Psychol. Educ. 2007; 10 (4):483-93.

12. The WHOQOL Group. The development of the World Health Organization Quality of Life Assessment Instrument (the WHOQoL). In: Orley J, Kuyken W, editors. Quality of Life Assessment: International Perspectives. Heidleberg: Springer-Verlag; 1994.

13. Pintrich PR. A conceptual framework for assessing motivation and self-regulated learning in college students. Educ. Psychol. Rev. 2004; 16 (4):385-407.

14. Pintrich PR, De Groot EV. Motivational and self-regulated learning components of classroom academic performance. J. Educ. Psychol. 1990; 82 (1):33-40.

15. Schunk DH, Pajares F. Competence Perceptions and Academic Functioning. In: Elliott A, Dweck $\mathrm{C}$, editors. Handbook of competence and motivation (pages 85-104). New York: Guilford; 2005.

16. Pintrich PR, Zusho A. Student motivation and self-regulated learning in the college classroom. In: Perry RP, Smart JC, editors. The scholarship of teaching and learning in higher education: An evidence-based perspective. Dordrecht, The Netherlands: Springer; 2007. p. 731-810.

17. Raj SR, Simpson CS, Hopman WM, Singer MA. Health-related quality of life among final-year medical students. CMAJ. 2000;162(4):509-10. http://www.cmaj.ca.ezproxy.auckland.ac.nz/cgi /reprint/162/4/509 [September 10, 2010]

18. Prins JT, Gazendam-Donofrio SM, Dillingh GS, van de Wiel HBM, van der Heijden FMMA, Hoekstra-Weebers JEHM. The relationship between reciprocity and burnout in Dutch medical residents. Med. Educ. 2008; 42 :721-8. 
19. Akins RB. Motivation of Asian Americans to study medicine: A pilot study. Academic Leadership. 2007;5(1). http://www. academicleadership.org/emprical_research/Mo tivation_of_Asian_Americans_to_Study_Medi cine_A_Pilot_Study.shtml [August 4, 2010]

20. The WHOQOL Group. Development of the World Health Organization WHOQOL-BREF quality of life assessment. Psychol. Med. 1998; 28 (3):551-8.

21. Billington R, Landon J, Krägeloh CU, Shepherd D. The New Zealand World Health Organization Quality of Life (WHOQOL) Group. $N Z$ Med. $J$. 2010; 123 (1315):65-70.

22. Ferguson E, James D, Madeley L. Factors associated with success in medical school: Systematic review of the literature. $B M J$. 2002; 324 :952-7.

23. Pelaccia T, Delplancq H, Triby E, Bartier J-C, Leman CC, Dupeyron J-P. Impact of training periods in the emergency department on the motivation of health care students to learn. Med. Educ. 2009; 43 (5):462-70.

24. Rieber N, Betz L, Enck P, Muth E, Nikendei C, Schrauth M, et al. Effects of medical training scenarios on heart rate variability and motivation in students and simulated patients. Med. Educ. 2009;43(6):553-6.

25. Armstrong D, Ashworth M. When questionnaire response rates do matter: A survey of general practitioners and their views of NHS changes. Brit. J. Gen. Pract. 2000; 50 :479-80.

26. The University of Auckland: Faculty of Medical and Health Sciences. Undergraduate study at the FMHS.; 2009 [updated July 2; cited 2009 November 24]. Available from: http://www.fmhs.auckland.ac.nz/faculty/under grad/default.aspx.

27. Davis C, Thake J, Vilhena N. Social desirability biases in self-reported alcohol consumption and harms. Addictive Behav. 2010;35(4):302-11.

28. Hodgson C, Teherani A, Guiton G, Wilkerson L. The relationship between student anonymity and responses from two medical schools on the Association of American Medical Colleges' Graduation Questionnaire. Acad. Med. 2002;77(10):S48-S50.

29. Murphy B, Herrman H, Hawthorne G, Pinzone T, Evert H. Australian WHOQOL Instruments: User's manual and interpretation guide. Melbourne: Australian WHOQOL Field Study Centre; 2000.

30. Field A. Discovering statistics using SPSS. 2nd ed. London: Sage; 2005.
31. Ohsako T, Sawano Y. The situation in Japan. In: Tikkanen T, Nyhan B, editors. Promoting lifelong learning for older workers: An international overview (pages 90-107). Luxembourg: Office for Official Publications of the European Communities 2006.

32. The WHOQoL Group. The World Health Organization quality of life assessment (WHOQOL): Development and general psychometric properties. Soc. Sci. Med. 1998; 46 (12):1569-85.

33. White CB, Gruppen LD. Self-regulated learning in medical education. Edinburgh: Association for the Study of Medical Education (ASME); 2007.

34. Boekaerts M. Being concerned with well-being and with learning. Educ. Psychol. 1993; 28:14867.

35. Henning MA, Hawken SJ, Hill AG. The quality of life of New Zealand doctors and medical students: What can be done to avoid burnout? New Zealand Med J. 2009;122(1307):102-10.

36. Choi N. Self-efficacy and self-concept as predictors of college students' academic performance. Psychol. Schools. 2005; 42 (2):197-205.

37. Marsh HW. Causal ordering of academic selfconcept and academic achievement: a multiwave, longitudinal panel analysis. J. Educ. Psych. 1990; 82 (4):646-56.

38. Rodriguez C. The impact of academic selfconcept, expectations and the choice of learning strategy on academic achievement: the case of business students. High. Educ. Res. Develop. 2009; 28 (5):523-39.

39. Turner JL, Dankoski ME. Objective Structured Clinical Exams: A Critical Review. Fam. Med. 2008; 40 (8):574-8.

40. Ford-Gilboe M, Laschinger HKS, LaforetFliesser Y. The effect of a clinical practicum on undergraduate nursing students' self-efficacy for community-based family nursing practice. $J$. Nurs. Educ. 1997; 36 :212-9.

41. Jackson JW. Enhancing self-efficacy and learning performance. J. Experiment. Educ. 2002; 70 (3):243-54.

42. Margolis H, McCabe PP. Self-efficacy: A key to improving the motivation of struggling learners. Prevent. School Failure. 2003; 47 (4):162-9.

43. Opacic DA. The relationship between selfefficacy and student physician assistant clinical performance. J. Allied Health. 2003; 32 (3):158-66.

44. Pintrich PR. A motivational science perspective on the role of student motivation in learning and teaching contexts. J. Educ. Psychol. 2003; 95 (4):667-86. 